\title{
Transduction of Penicillinase Production and Methicillin Resistance-Enterotoxin B Production in Strains of Staphylococcus aureus
}

\author{
By KATHERINE DORNBUSCH AND H. O. HALLANDER \\ Institute of Medical Microbiology, University of Uppsala, Uppsala, Sweden
}

(Received 8 May 1972; revised 23 October 1972)

\begin{abstract}
SUMMARY
It is suggested that wild strain DU 49I6 of Staphylococcus aureus harbours at least two plasmids. One of them is responsible for penicillinase production and resistance to metallic ions and the other for methicillin and cephalothin resistance together with enterotoxin B production. These properties were eliminated en bloc with acridines as well as separately at different rates. Transductions were performed to restore the eliminated characters with typing phages 29 and 88 . Recombination of the markers for penicillinase production and methicillin resistance on the transduced fragment seems advantageous for selection of methicillin resistance.
\end{abstract}

\section{INTRODUCTION}

Some hereditary characters in staphylococci are lost spontaneously at a relatively high frequency which may, however, be increased by growth in the presence of acridine dyes (Mitsuhashi, Morimura, Kono \& Oshima, I963; Hashimoto, Kono \& Mitsuhashi, I964), ethidium bromide (Bouanchaud, Scarizzi \& Chabbert, 1969) or at high temperatures (May, Houghton \& Perret, I964). The elimination of genetic determinants at high frequency is often taken to imply their extrachromosomal nature.

A number of different types of plasmids have been identified in staphylocci by genetical analysis. They include plasmids conferring resistance to antibiotics (Fairbrother, Parker \& Eaton, 1954; Novick, 1963; Chabbert, Baudens \& Gerbaud, I964; May et al. 1964; Dornbusch, Hallander \& Löfquist, I969; Novick, I969), heavy metal ions (Richmond \& John, 1964; Novick 1967), toxin and pigment production (Serwin-Massieu, I961; Dornbusch, Hallander \& Löfquist, 1969). Some strains carry more than one plasmid and strains carrying two different penicillinase plasmids have been constructed artificially (Richmond, 1968) as have strains carrying both chromosomal and extrachromosomal genes for penicillinase production (Asheshov, 1969).

In a previous report a number of strains of Staphylococcus aureus were described in which the genes controlling methicillin resistance and production of enterotoxin B appeared to be associated. Both characters were lost after treatment with acriflavine and later restored by transduction (Dornbusch et al. 1969) and it was suggested that their determinants were located on a plasmid. One of these strains was studied further to establish this plasmid location. Transduction of methicillin resistance has recently been described by Cohen \& Sweeney (1970); its genetic determinant is located on the chromosome. 


\section{METHODS}

Strains of Staphylococcus aureus (Table I). Three mutants of a methicillin-resistant penicillinase-producing strain, DU49I6, isolated from an infected burn wound at the University Hospital, Uppsala, Sweden (Dornbusch et al. 1969) were isolated after acridine treatment. Two other strains, DU 3108 and DU 3287, isolated locally (Dornbusch et al. 1969), were used as recipients in transduction experiments, as was a strain RB I ( $\alpha$ pen $^{+}$Mut met-s), kindly supplied by Professor Mark Richmond, Bristol. This methicillin-sensitive (met-s) strain harbours a penicillinase plasmid of $\alpha$ type $\left(\alpha\right.$ pen $\left.^{+} M u t\right)$ (Richmond, I968) which produces much less of the enzyme $(5 \%)$ than wild-type.

Sensitivity tests. The disc diffusion test (Ericsson, 1960) was used for all antibiotics. Resistance to benzylpenicillin, methicillin, cephalothin and erythromycin was also determined by a plate-dilution test (Barber \& Waterworth, 1964). Resistance to cadmiumsulphate and mercuric acetate was determined by plate dilution (Moore, I960). The minimum inhibitory concentration (m.i.c.) is the lowest concentration which completely inhibits growth.

Assay of toxins. Qualitative and quantitative assays for the production of $\alpha-, \beta$-, and $\delta$ haemolysins, lipase, free coagulase and enterotoxin B were determined as described by Hallander (1965). DNase production was determined by growing bacteria on DNA-agar plates (Di Salvo, I958). After $24 \mathrm{~h}$ at $37^{\circ} \mathrm{C}$, undigested DNA was developed by flooding the plates with I N-sulphuric acid.

Treatment with acridines. This was performed as described by Dornbusch et al. (1969).

Detection of penicillinase production. The starch agar method of Dyke, Jevons \& Parker (1966) was used.

Phage typing. This was carried out by the method of Blair \& Williams (I96I) using the standard set of typing phages and the phage 88 .

Propagation of phage for transduction. Typing phages 29 and 88 were propagated on donor strains by the soft-agar overlay method of Swanstrom \& Adams (I95I). Lysates were sterilized by Millipore filtration $(0.45 \mu \mathrm{m}$ pore size $)$ and phages titre determined as plaque-forming units (p.f.u.) $/ \mathrm{ml}$; they ranged from $\mathrm{I} \cdot 4 \times 10^{7}$ to $2 \cdot 7 \times 10^{9}$.

Transduction. The method of Asheshov (1966) was used. The plates in transducing the met-r marker were incubated at 30 or $37^{\circ} \mathrm{C}$ (Annear, I968). In transduction of penicillinase production or cadmium resistance, all plates were incubated at $37^{\circ} \mathrm{C}$. Controls, including sterility tests of the phage lysate and tests for back mutation in the absence of transducing phage, were performed with each experiment.

Media. (i) For selection of penicillin or $\mathrm{Cd}^{2+}$-resistant transductants: nutrient agar (Difco) with $0 . \mathrm{I}$ or $10 \mu \mathrm{g}$ benzylpenicillin $/ \mathrm{ml}$; or with $5.0 \times \mathrm{IO}^{-5} \mathrm{M}$ or $7.5 \times \mathrm{IO}^{-5} \mathrm{M}_{-\mathrm{CdSO}}$. (ii) For selection of methicillin-resistant transductants (salt agar): $0.8 \%(\mathrm{w} / \mathrm{v})$ nutrient broth (Difco, Detroit, Michigan, U.S.A.); $\mathrm{I} \cdot \mathrm{I} \%$ (w/v) Davis Agar (Davis Gelatine Ltd, Warwick); $5 \%$ (w/v) sodium chloride; $25 \mu \mathrm{g}$ methicillin $/ \mathrm{ml}$. (iii) Nutrient broth (Difco) was used for bacterial broth cultures.

Lysogeny. A strain was considered to be lysogenic if it was immune to the lysogenizing phage and produced a phage that lysed its non-lysogenic parent. For induction of lysogenic strains the method of Kjems (1955) was used.

Efficiency of detection of methicillin resistance. This was to test whether the presence of methicillin-resistant bacteria in an otherwise sensitive population could inactivate the methicillin in the salt agar plates and was necessary to establish that all methicillin-resistant colonies resulted from transduction and were not satellite colonies. Sensitive bacteria 
Table I. Phenotypes of the four variants of strain DU 4916, the wild-type strains DU 3108 and DU 3287 and the mutant RB I of Staphylococcus aureus

Production of

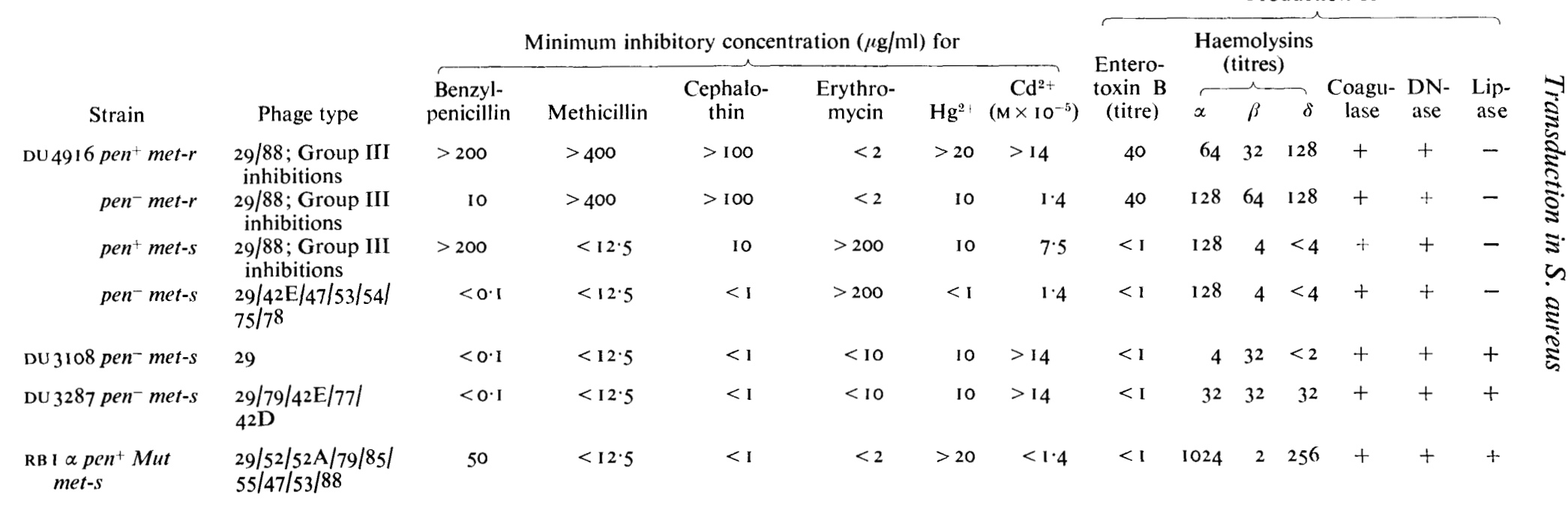

$p^{p} n^{+}$, producer of penicillinase; pen $^{-}$, non-producer of penicillinase; met-r, methicillin-resistant; met-s, methicillin-sensitive; Mut, mutant; $\mathrm{Hg}^{2+}$, mercuric ion; $\mathrm{Cd}^{2+}$, cadmium ion. 
(strains DU49I6 pen ${ }^{+}$met-s and pen-met-s) were mixed with $0.1 \%$ resistant bacteria (DU 4916 pen $^{+}$met-r) in nutrient broth and incubated at $37^{\circ} \mathrm{C}$ for $30 \mathrm{~min}$. Suitable dilutions of the mixture were plated on salt agar with or without $25 \mu \mathrm{g}$ methicillin/ml and incubated for $48 \mathrm{~h}$ at $30^{\circ} \mathrm{C}$. As controls the sensitive and resistant cultures were incubated and plated separately in the same way.

\section{RESULTS}

Loss of genetic characters after growth with acridine dyes. DU $49 \mathrm{I} 6$ is a methicilin-resistant strain of Staphylococcus aureus which is resistant to $\mathrm{Hg}^{2+}$ and $\mathrm{Cd}^{2+}$ and produces penicillinase, enterotoxin $\mathrm{B}, \alpha$-, $\beta$ - and $\delta$-haemolysins, coagulase and DNase but not lipase (Table I, line I). It will be referred to as DU 4916 pen $^{+}$met-r. Methicillin-sensitive mutants could be isolated from this strain at a frequency of $2.6 \%$ after growth in acriflavine (Dornbusch et al. 1969). These mutants (pen ${ }^{+}$met-s) lost simultaneously production of enterotoxin B and haemolytic activity for sheep and human erythrocytes (Table I, line 3). They also differed from the parent strain in that they show cephalothin sensitivity and inducible erythromycin resistance. Following further treatment of DU 4916 pen $^{+}$met-r with 5 -aminoacridine. $\mathrm{HCl} 0.8 \%$ of the bacteria were pen met-r and $0.05 \%$ pen $^{-}$met-s respectively (Table I, lines 2 and 4 ). Loss of penicillinase production in pen- met-r was associated with reduced m.i.c. for cadmium and mercuric ions. This mutant remained resistant to low levels of penicillin in agreement with other comparable data (Richmond, Parker, Jevons \& John, 1964; Dyke et al. 1966; Hewitt \& Parker, I968; Dyke, 1969) but still produced enterotoxin $\mathrm{B}$ and $\beta$-haemolysin. The pen ${ }^{-}$met-s mutant showed simultaneous loss of resistance to cadmium and to mercuric ions, loss of ability to produce penicillinase, enterotoxin B or to haemolyse sheep and human red blood cells, gained resistance to erythromycin, and was greatly changed in its phage typing pattern. Revertants to methicillin resistance or penicillinase production occurred either spontaneously or after treatment with acridines at a frequency greater than $\mathrm{IO}^{-8}$.

The characteristics of the three mutants pen ${ }^{+}$met-s, pen- met-r, and pen- met-s suggested that these markers were present in two separate genetic groups in the parent strain DU 49I6 pen $^{+}$met-r. One of these resembles the penicillinase plasmids described in other strains of staphylococci (Richmond, I968) and appears to carry the genetic determinants for penicillinase production linked to those controlling resistance to cadmium and mercury ions. The other genetic group appears to carry the genes controlling methicillin resistance, production of enterotoxin $\mathrm{B}, \beta$-haemolysin and a gene conferring at least partial resistance to mercuric ions. It also seems to carry some genetic factor which blocks expression of inducible erythromycin resistance (Weaver \& Pattee, I964).

\section{Transduction experiments}

To verify the suggestion that strain DU 4916 pen $^{+}$met-r harbours at least two plasmids, transduction experiments were performed to restore the eliminated characters and to examine their genetic association. Typing phages 29 and 88 were used as transducing vectors. The frequency of reverse mutation in the absence of transducing phage was less than $10^{-10}$ in all controls.

Transduction of methicillin resistance with phage 29. Strain DU $49 \mathrm{I} 6$ pen $^{+}$met-r was used as donor and the mutants pen ${ }^{-}$met-s and pen ${ }^{+}$met-s as recipients with phage at multiplicities of infection of 0.5 to $\mathrm{I} \cdot 0$. Selection was made on salt agar medium containing $25 \mu \mathrm{g}$ methicillin/ml. Methicillin-resistant transductants were obtained in both crosses (Table 2) and the frequencies of transduction were $7.0 \times 10^{-7}$ and $5.0 \times 10^{-7}$ respectively. About 100 transductants from each cross were examined. All were resistant to cephalothin, produced 
Table 2. Transduction of methicillin resistance with phages 29 and 88

Production by the transductants of

\begin{tabular}{|c|c|c|c|c|c|c|c|c|c|c|c|c|}
\hline \multirow[b]{3}{*}{$\begin{array}{l}\text { Donor } \\
\text { strain of } \\
\text { DU } 4916\end{array}$} & \multirow[b]{3}{*}{$\begin{array}{l}\text { Recipient } \\
\text { strain of } \\
\text { DU } 49 \text { I } 6\end{array}$} & \multirow[b]{3}{*}{ Phage } & \multirow[b]{3}{*}{$\begin{array}{c}\text { Frequency } \\
\text { of trans- } \\
\text { duction }\end{array}$} & \multirow{3}{*}{$\begin{array}{l}\text { No. of } \\
\text { trans- } \\
\text { ductants }\end{array}$} & \multirow{2}{*}{\multicolumn{5}{|c|}{ Minimum inhibitory concentration of the transductants $(\mu \mathrm{g} / \mathrm{ml})$ for }} & \\
\hline & & & & & & & & & & & & Hacmolytic \\
\hline & & & & & $\begin{array}{l}\text { Methi- } \\
\text { cillin }\end{array}$ & $\begin{array}{l}\text { Cepha- } \\
\text { lothin }\end{array}$ & $\begin{array}{l}\text { Erythro- } \\
\text { mycin }\end{array}$ & $\mathrm{Hg}^{2+}$ & $\underset{\left(\mathrm{M} \times 10^{-5}\right)}{\mathrm{Cd}^{2+}}$ & $\begin{array}{l}\text { Peni- } \\
\text { cillinase }\end{array}$ & $\begin{array}{l}\text { Entero- } \\
\text { toxin B } \\
\text { (titre) }\end{array}$ & $\begin{array}{c}\text { activity on sheep } \\
\text { erythrocytes } \\
\text { (titre) }\end{array}$ \\
\hline \multirow[t]{2}{*}{ pen met-r } & pen met-s & 29 & $7 \cdot 0 \times 10^{-7}$ & 338 & $>200$ & $>100$ & $\begin{aligned} & <2(94 \%) \\
> & 200(6 \%)\end{aligned}$ & $>40$ & $>14$ & + & 40 & $\begin{array}{r}32(60 \%) \\
<4(40 \%)\end{array}$ \\
\hline & $p e n^{+}$met-s & & $5.0 \times 10^{-7}$ & 235 & $>200$ & $>100$ & $<2$ & $>40$ & $>14$ & + & 40 & $\begin{array}{r}32(30 \%) \\
>4(70 \%)\end{array}$ \\
\hline \multirow[t]{2}{*}{$p e n^{+} m e t-r$} & pen met-s & 88 & $1.0 \times 10^{8}$ & 5 & $>200$ & $>100$ & $\begin{array}{r}>2(60 \%) \\
>200(40 \%)\end{array}$ & $\begin{array}{r}>40(60 \%) \\
10(40 \%)\end{array}$ & $\begin{array}{r}>\mathrm{I} 4(60 \%) \\
\mathrm{I} \cdot 4(40 \%)\end{array}$ & $\begin{array}{l}+(60 \%) \\
-(40 \%)\end{array}$ & $\begin{array}{r}40(60 \%) \\
<1(40 \%)\end{array}$ & 8 \\
\hline & $p^{2} n^{+}$met-s & & $1.0 \times 10^{-8}$ & 5 & $>200$ & $>100$ & $<2$ & $>40$ & $>14$ & + & 40 & 8 \\
\hline
\end{tabular}

Table 3. Transduction of penicillinase production with phage 29

Abbreviations as in Table 1.

Production by the transductants of

Minimum inhibitory concentration of the transductants $(\mu \mathrm{g} / \mathrm{ml})$ for

Donor
strains of

DU 49 I 6

pen met-r DU49I6 pen met-s

DU 4916 pen met- $r$

DU 3108 pen- met-s

DU 3287 pen' met-s

pen met-s DU49I6 pen met-s

DU 4916 pen- met-r

DU 3287 pen met-s

Frequency of
transduction
$3.3 \times 10^{-5}$
$1.4 \times 10^{-5}$
$7.4 \times 10^{-7}$
$6.3 \times 10^{-6}$
$4.0 \times 10^{-7}$
$8.0 \times 10^{-6}$
$8.0 \times 10^{-10}$
$1.5 \times 10^{-9}$

C.C. $\mathrm{Cd}^{2}$

Met
$<12.5$

$>400(8 / 92)$

$<12 \cdot 5(84 / 92)$

$>400(7 / 87)$

$<12.5(80 / 87)$

\section{$<$ I}

$>100(8 / 92)$

$<$ I $(84 / 92)$

$>400(7 / 87)$

$<12.5(80 / 87)$

$>200$
$<10$
$<10$
$>$
$>200$
$<10$
$<10$
$<10$

$\begin{array}{rc}>20 & >14 \\ >20 & >14 \\ >20 & \\ >20 & \\ & \\ & \\ 10 & >5-14< \\ 10 & >5-14< \\ 10 & \\ 10 & \end{array}$

Haemolytic

Enterotoxin B activity for sheep

(titre)

(titre)

$<$ I

$40(8 / 92)$

$<$ I $(84 / 92)$

$40(7 / 87)$

$<$ I $(80 / 87)$ 
penicillinase, enterotoxin $\mathrm{B}$ and were resistant to $\mathrm{Cd}^{2+}$ and $\mathrm{Hg}^{2+}$ and some possessed haemolytic activities for sheep and human erythrocytes. Ninety-four out of 100 transductants from the first cross and all from the second differed from the recipient in that they were sensitive to erythromycin. Transduction to methicillin resistance also resulted in change in the phage typing pattern. The transductants were non-typable, but some were weakly lysed by phage 88 . Resistance to typing phage 29 , to which the recipient was sensitive, suggested that the transductants might have become lysogenized by the transducing phage (Rountree, 1959). However, only three out of 30 transductants from the first cross were inducible. In the second cross all transductants were immune to the transducing phage, and were non-inducible.

Attempts were also made to transduce methicillin resistance from the mutant pen- met-r, selecting on either methicillin-salt agar $(25 \mu \mathrm{g} / \mathrm{ml})$ or benzylpenicillin agar (Io $\mu \mathrm{g} / \mathrm{ml})$. No methicillin-resistant transductants were obtained from the crosses $p^{+} n^{+}$met-s $\times$phage $29 /$ pen- met-r or pen- met-s $\times$ phage $29 /$ pen $^{-}$met-r.

Transduction of methicillin resistance with phage 88 . Methicillin-resistant transductants were obtained from the crosses pen ${ }^{-}$met $-s \times$ phage $88 /$ pen $^{+}$met-r and pen ${ }^{+}$met $-s \times$ phage $88 /$ pen $^{+}$met-r at a frequency of $\mathrm{I} \times \mathrm{IO}^{-8}$ (Table 2). All transductants were resistant to cephalothin as well. Three out of the five transductants from the first cross and all five from the second produced penicillinase and enterotoxin $\mathrm{B}$ and were resistant to $\mathrm{Cd}^{2+}$ and $\mathrm{Hg}^{2+}$. They differed from the recipient in that they were sensitive to erythromycin. The two remaining methicillin-resistant transductants from the first cross did not produce penicillinase or enterotoxin $\mathrm{B}$ and were sensitive to $\mathrm{Cd}^{2+}$ and $\mathrm{Hg}^{2+}$ and showed inducible erythromycin resistance. Transduction to methicillin resistance in these two crosses did not result in an alteration of the phage typing pattern.

Attempts to transduce methicillin resistance from strain pen- met-r into the pen ${ }^{-}$met-s or pen ${ }^{+}$met-s strains were unsuccessful.

Plating efficiency of methicillin resistance. There was no stimulation of growth of methicillin-sensitive cells when a mixture of sensitive and resistant cells were plated on methicillin-salt agar plates. Since the proportion of resistant and sensitive bacteria was maintained after plating, the resistant bacteria did not apparently eliminate methicillin from the agar.

Transduction of penicillinase production or cadmium resistance with typing phage 29. In order to detect the presence of a penicillinase plasmid, the strains DU 4916 pen ${ }^{+}$met-r and $p e n^{+}$met-s were used as donors and the penicillinase-negative variants of the same strain and two penicillinase-negative, methicillin-sensitive wild strains of Staphylococcus aureus DU 3108 pen $^{-}$met-s and DU 3287 pen $^{-}$met-s as recipients. Selection was made on nutrient agar containing benzylpenicillin or cadmium sulphate.

The frequencies of penicillinase producing transductants were in the range of $3.3 \times 10^{-5}$ to $8 \times 10^{-10}$ (Table 3). All the transductants were both $\mathrm{Cd}^{2+}$ and $\mathrm{Hg}^{2+}$ resistant. In the crosses DU 3108 pen $^{-}$met-s $\times$phage $29 /$ pen $^{+}$met-r and DU 3287 pen $^{-}$met- $s \times$ phage $29 /$ pen $^{+}$ $m e t-r 8 \%$ co-transduction of methicillin resistance and toxin production was obtained. The $p n^{+}$met-r transductants were lysed by phages 29 and 88 as was the donor, whereas all the pen $^{+}$met-s transductants showed the same typing patterns as the respective recipients. Cotransduction of methicillin resistance and penicillinase production on methicillin-salt agar was not obtained with DU3108 pen- met-s and DU 3287 pen-met-s as recipients. $\mathrm{Cd}^{2+}$ resistant transductants were obtained from these crosses with selection on cadmium agar. The frequencies of transduction were between $3.4 \times \mathrm{IO}^{-5}$ and $\mathrm{I} \cdot 0 \times \mathrm{IO}^{-7}$. All transductants produced penicillinase and were resistant to $\mathrm{Hg}^{2+}$. 
Table 4. Transduction of methicillin resistance or penicillinase production with mixed phage lysates

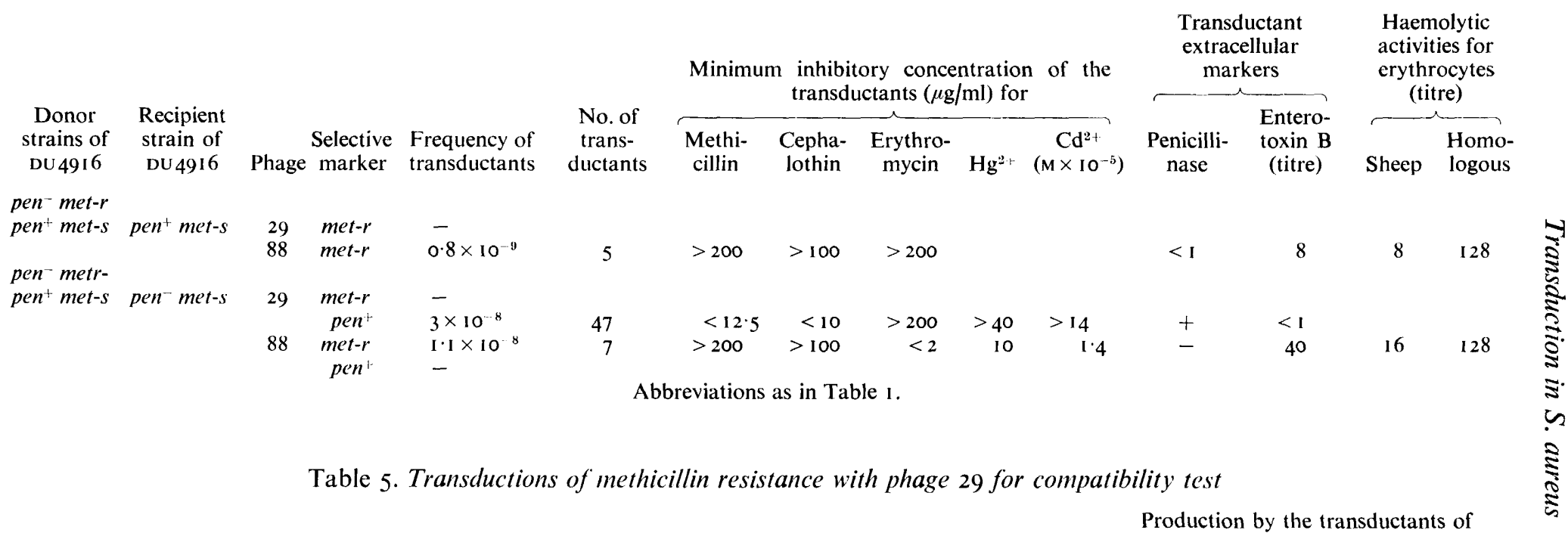

\begin{tabular}{|c|c|c|c|c|c|c|c|c|c|c|c|}
\hline \multirow{3}{*}{$\begin{array}{l}\text { Donor } \\
\text { strain of } \\
\text { DU } 4916\end{array}$} & \multirow{3}{*}{$\begin{array}{l}\text { Recipient } \\
\text { strain of } \\
\text { DU } 4916\end{array}$} & \multirow[b]{3}{*}{$\begin{array}{l}\text { Frequency of } \\
\text { transduction }\end{array}$} & \multirow[b]{3}{*}{$\begin{array}{c}\text { No. of } \\
\text { transductants }\end{array}$} & \multirow{2}{*}{\multicolumn{5}{|c|}{$\begin{array}{l}\text { Minimum inhibitory concentration of the transductants } \\
\qquad(\mu \mathrm{g} / \mathrm{ml}) \text { for }\end{array}$}} & \\
\hline & & & & & & & & & \multirow[b]{2}{*}{$\begin{array}{l}\text { Penicilli- } \\
\text { nase of }\end{array}$} & \multirow[b]{2}{*}{$\begin{array}{l}\text { Entero- } \\
\text { toxin B }\end{array}$} & \multirow{2}{*}{$\begin{array}{c}\text { Haemolytic } \\
\text { activity } \\
\text { on sheep } \\
\text { erythrocytes } \\
\text { (titre) }\end{array}$} \\
\hline & & & & Methicillin & Cephalothin & $\begin{array}{l}\text { Erythro- } \\
\text { mycin }\end{array}$ & $\mathrm{Hg}^{2+}$ & $\underset{\left(\mathrm{M} \times \mathrm{IO}^{-5}\right)}{\mathrm{Cd}^{2+}}$ & & & \\
\hline pen $^{+}$met-r & pen $^{+}$Mut met-s & $1 \cdot 9 \times 10^{-7}$ & 97 & 30 & 10 & $>200$ & $>40$ & $<\mathrm{I} \cdot 4$ & Mutant type & $<\mathrm{I}$ & $<2$ \\
\hline
\end{tabular}


Transduction of methicillin resistance and penicillinase production using mixed phage lysates. As methicillin resistance could only be transduced from penicillinase-producing donors, co-transfer was investigated further. Typing phage 29 was propagated on strains DU 4916 pen $^{-}$met-r and DU 49I 6 pen $^{+}$met-s separately to a titre of $10^{9}$ p.f.u. $/ \mathrm{ml}$. The sterile lysates were mixed and used to transduce the strains DU49r6 pen ${ }^{+}$met-s and DU 49r6 pen ${ }^{-}$met-s. Selection was made on methicillin-salt or penicillin agar. No methicillinresistant transductants were obtained from the crosses pen ${ }^{+}$met-s $\times$phage $29 / p^{-} n^{-}$met-r/ pen $^{+}$met-s or pen ${ }^{-}$met-s $\times$phage $29 /$ pen $^{-}$met-r/pen ${ }^{+}$met-s. Penicillinase-producing transductants resistant to both $\mathrm{Cd}^{2+}$ and $\mathrm{Hg}^{2+}$ were, however, found at the low frequency of $3 \times 10^{-8}$ in the cross pen- met-s $\times$ phage $29 /$ pen $^{-}$met-r/pen ${ }^{+}$met-s with no linked transfer of met-r (Table 4).

The transduction crosses were repeated using the mixed phage 88 lysates from the two donor strains. Methicillin-resistant transductants were obtained at a frequency of $0.8 \times 10^{-9}$ using the mutant pen $n^{+}$met-s as recipient and at $\mathrm{I} \cdot \mathrm{I} \times \mathrm{IO}^{-8}$ using pen- met-s as recipient (Table 4). The transductants from the first cross produced no enterotoxin B but possessed some haemolytic activity for sheep and human erythrocytes and were resistant to cephalothin as well. They were still inducibly erythromycin resistant and lysed by the phages 29 and 88 as was the recipient. The met-r transductants from the second cross produced enterotoxin B and possessed haemolytic activity but had no penicillinase. They were also sensitive to $\mathrm{Cd}^{2+}$ and $\mathrm{Hg}^{2+}$. All transductants were resistant to cephalothin but sensitive to erythromycin. Their phage type pattern was the same as the recipient. When selection was made on penicillin agar, the pen+ marker could not be transduced into the pen- met-s strain.

Transduction of methicillin resistance into a strain harbouring a defined mutated penicillinase plasmid. To detect any possible association between methicillin resistance and penicillinase production in strain DU49I6, another strain, RBI ( $\alpha$ pen $^{+}$Mut met-s), was used for compatibility studies (Richmond, I968). This strain harbours an $\alpha$-plasmid as does the strain DU 4916 pen $^{+}$met-r, but the former is a mutant which produces small amounts of penicillinase as compared with wild-type. This plasmid was transferred into strain DU 4916 pen- met-s with phage 29 at a frequency of $\mathrm{I} \cdot 2 \times \mathrm{IO}^{-5}$. One of the penicillinase transductants from this cross was then used as recipient in the cross DU 49I6 pen ${ }^{+}$Mut met-s $\times$phage 29/DU 49I 6 $p^{+} n^{+}$met-r with selection on methicillin-salt agar. Methicillin-resistant transductants were obtained at a frequency of $\mathrm{I} \cdot 9 \times \mathrm{IO}^{-7}$ (Table 5). The m.i.c. of the transductants for methicillin was, however, only $30 \mu \mathrm{g} / \mathrm{ml}$ as compared with more than 200 for the transductants from other crosses (Tables 2 and 4). All transductants produced penicillinase of the mutant type (i.e. like the recipient) but they did not produce enterotoxin $\mathbf{B}$ or possess haemolytic activities. They were all erythromycin resistant and sensitive to $\mathrm{Cd}^{2+}$ but resistant to $\mathrm{Hg}^{2+}$ and their phage type pattern was unchanged. No methicillin-resistant colonies were obtained when the same transduction crosses were repeated using phage 88 .

Treatment of methicillin-resistant transductants with acriflavine. Since almost all met-r transductants were co-transduced to penicillinase production, a pen ${ }^{+}$met-r transductant was treated with acriflavine to test if the suggested recombination of the markers was stable. Loss of $m e t-r$ was obtained among transductants from the cross DU 49 I 6 pen- met $-s \times$ phage 29/DU 4916 pen $^{+}$met-r at a frequency of $0.14 \%(3 / 2004)$ and of the pen $n^{+}$marker at a frequency of $0.9 \%(18 / 2000)$.

Since the pen ${ }^{+}$Mut met-r transductants from the cross DU $49 \mathrm{I} 6$ pen $^{+}$Mut met-s phage 29/ DU 4916 pen $^{+}$met-r did not show haemolytic activities for sheep erythrocytes, met-s colonies could not be picked from $\mathrm{I} \%$ sheep blood agar plates after acriflavine treatment (Dornbusch et al. 1969). However, $0.3 \%$ (6/2000) of colonies were penicillinaseless 
after acriflavine treatment by the replica plating technique with no co-loss of methicillin resistance.

\section{DISCUSSION}

The appearance of sensitive derivatives after treatment of strain DU $49 \mathrm{I} 6$ with acridines may imply the presence of two plasmids (Table I). If so, one of them is a typical penicillinase plasmid with the genetic determinants for penicillinase production and resistance to $\mathrm{Hg}^{2+}$ and $\mathrm{Cd}^{2+}$ (Novick, 1967; Richmond, 1968) and the other a plasmid-controlling methicillin and cephalothin resistance, enterotoxin $\mathrm{B}$ and $\beta$-haemolysin production and maybe some factor which blocks expression of resistance to erythromycin. A deletion in a chromosomal control locus for one or both genes caused by acridines has, however, not been excluded. The loss of $\beta$-haemolysin was always accompanied by a loss in the ability to haemolyse human erythrocytes. As purified $\beta$-lysin as well as $\alpha$-lysin has only a slight effect on human cells, this phenomenon may be explained by a synergistic effect or by a simultaneous loss of $\delta$-lysin as well (Hallander \& Bengtsson, 1967). Loss of methicillin resistance from strains of Staphylococcus aureus after growth at $43{ }^{\circ} \mathrm{C}$ has recently been reported (Al Salihy \& James, I972) as a result of changed surface properties at different temperatures. The authors suggest that the methicillin resistance genes are carried on a plasmid.

Transduction experiments (Table 3) confirm that strain DU 49 I 6 carries a penicillinase plasmid, i.e. transduction of $\mathrm{pen}^{+}$and $\mathrm{Cd}^{2+}$ resistance regardless of whether selection for penicillin or cadmium resistance is made. These markers were also easily transduced to other strains. However, there was less success in transducing the methicillin resistance marker alone. No transductants were isolated when the strain DU 49I6 pen- met-r was used as donor.

Most methicillin-resistant transductants were also penicillinase producers (Table 2). Apparently methicillin-resistant transductants are most easily selected when they are also transduced to penicillinase production. Using typing phages 29 or 88 , transduction of methicillin resistance succeeded when both donor and recipient were pen $^{+}$and when the donor was pen $^{+}$and the recipient pen-, but in the latter case, with few exceptions, met-r was co-transduced with pen ${ }^{+}$. The results suggest that the markers for pen $n^{+}$met-r might recombine on the transduced fragment for transduction of methicillin resistance. It was also clear from the plating efficiency experiments that all met-r transductants were real transductants and not just satellite colonies due to breakdown of methicillin in the plates around a met-r colony. In two crosses with recipients which were not derived from the strain DU 49I6, methicillin resistance and toxin production were $8 \%$ co-transduced with penicillinaseproduction (Table 3). This fact further supports the suggestion that the two linkage groups can recombine.

With a mixture of phage 88 lysates propagated separately on the donors pen ${ }^{-}$met- $r$ and $p^{+} n^{+}$met-s, methicillin resistance and enterotoxin B production were, however, transduced into pen- met-s at low frequencies (Table 4) with no co-transduction of penicillinase production. When selecting on penicillin-agar no transductants could be obtained. This might be a dilution effect, since the phage lysate after propagation on pen $n^{+}$met-s was mixed with that propagated on pen- met-r. These facts may further support the suggestion that if the $p n^{+}$met-r markers are recombined on the transduced fragment the frequency of transduction of methicillin resistance and toxin production is stimulated. This recombination does not seem to be a stable event since acriflavine treatment of pen ${ }^{+}$met-r transductants resulted in loss of the two markers at different rates. Methicillin resistance was, however, also separately transduced, though only partially (Table 5) when strain DU49I6 pen+ Mut met-s 
was used as recipient. There was no co-transfer of either wild-type penicillinase or enterotoxin B production. The transductants were resistant to erythromycin like the recipient. In this case the linkage group for methicillin resistance has evidently been deleted, leaving the remaining part together with markers for toxin and enzyme production outside the phage head (Wood \& Henninger, I969).

The genetic markers for methicillin resistance and mutant penicillinase production in these transductants were shown to be located in separate linkage groups since enzyme production could be eliminated after acriflavine treatment with no co-ordinate loss of methicillin resistance. Transduction of chromosomal methicillin resistance has been described in another system (Cohen \& Sweeney, I970).

In transduction of methicillin resistance nutrient agar was unsatisfactory but transductants were obtained on hypertonic salt agar medium. Thus the nature of the expression of the met-r marker complicates the selection technique. Transduction of methicillin resistance was not stimulated at $30^{\circ} \mathrm{C}$ (Annear, I968; Hallander, Laurell \& Dornbusch, 1969; Hewitt, Coe \& Parker, I969).

The expression of inducible erythromycin resistance among the variants of strain DU 4916 will be studied further as well as the compatibility with known plasmid systems.

\section{REFERENCES}

AL SALIHY, S. M. \& JAMES, A. M. (1972). Loss of methicillin-resistance from resistant strains of Staphylococcus aureus. Lancet $\mathrm{i}, 33 \mathrm{I}-332$.

ANNEAR, D. I. (1968). Effect of temperature on resistance of Staphylococcus aureus to methicillin and some other antibiotics. Medical Journal of Australia i, 444-446.

Asheshov, E. (1966). Chromosomal location of the genetic elements controlling penicillinase production in a strain of Staphylococcus aureus. Nature, London 210, 804-806.

Asheshov, E. (1969). The genetics of penicillinase production in Staphylococcus aureus strain Ps 80. Journal of General Microbiology 59, 289-30I.

BARber, M. \& WATERWORTH, B. P. (1964). Penicillinase-resistant penicillins and cephalosporins. British Medical Journal ii, 344-349.

Blair, J. E. \& Williams, R. E. O. (I96I). Phage typing of Staphylococci. Bulletin of the World Health Organization 24, 77I-784.

Bouanchaud, D. H., SCARizzi, M. R. \& ChabberT, Y. A. (I969). Elimination by ethidium-bromide of antibiotic resistance in enterobacteria and staphylococci. Journal of General Microbiology 54, 41 7-425.

Chabbert, Y. A., Baudens, J. G. \& Gerbaud, G. R. (1964). Variations sous l'influence de l'acriflavine et transduction de la résistance à la kanamycine et au chloramphenicol chez les Staphylococques. Annales de l'Institut Pasteur 107, 678-690.

Cohen, S. \& SweEney, H. M. (1970). Transduction of methicillin resistance in Staphylococcus aureus dependent on an unusual specificity of the recipient strain. Journal of Bacteriology 104, I $158-1$ I 67.

Di Salvo, J. W. (1958). Deoxyribonuclease and coagulase activity of micrococci. U.S. Armed Forces Medical Journal of Medicine and Technology Bulletin 9, 191-196.

DornBusch, K., Hallander, H. O. \& LöFquist, F. (1969). Extrachromosomal control of methicillin resistance and toxin production in Staphylococcus aureus. Journal of Bacteriology 98, 35I-358.

DYKE, K. G. H. (1969). Penicillinase production and intrinsic resistance to penicillins in methicillin-resistant cultures of Staphylococcus aureus. Journal of Medical Microbiology 2, 26I-278.

Dyke, K. G. H., Jevons, M. P. \& PARker, M. T. (1966). Penicillinase production and intrinsic resistance to penicillins in Staphylococcus aureus. Lancet i, 835-838.

ERICSSON, H. (1960). Rational use of antibiotics in hospitals. Scandinavian Journal of Clinical and Laboratory Investigation 12 Suppl. 50.

Fatrbrother, R. W., Parker, L. \& Eaton, R. B. (1954). The stability of penicillinase-producing strains of Staphylococcus aureus. Journal of General Microbiology 10, 309-316.

Hallander, H. O. (1965). Production of large quantities of enterotoxin B and other staphylococcal toxins on solid media. Acta pathologica et microbiologica scandinavica 63, 299-305. 
Hallander, H. O. \& Bengtsson, S. (1967). Studies on the cell toxicity and species specificity of purified staphylococcal toxins. Acta pathologica et microbiologica scandinavica 63, 107-1 19.

Hallander, H. O., Laurell, G. \& Dornbusch, K. (1969). Determination of methicillin resistance of Staphylococcus aureus. Heterogeneity and its influence on the disc diffusion method. Scandinavian Journal of Infectious Diseases I, I69-I 74 .

Hashimoto, H., Kono, K. \& Mitsuhashi, S. (1964). Elimination of penicillin resistance of Staphylococcus aureus by treatment with acriflavine. Journal of Bacteriology 88, 26I-262.

Hewitt, J. H., CoE, A. W. \& Parker, M. T. (1969). The detection of methicillin resistance in Staphylococcus aureus. Journal of Medical Microbiology 2, 443-456.

HewITT, J. H. \& PARKER, M. T. (I968). Sensitivity of penicillinase-forming strains of Staphylococcus aureus and of their penicillinase-negative variants to cephaloridine, cephalothin, methicillin and benzylpenicillin. Journal of Clinical Pathology 21, 75-84.

KJEMS, E. (1955). Studies on streptococcal bacteriophages. Acta pathologica et microbiologica scandinavica 36, 433-440.

May, J. M., Houghton, R. H. \& Perret, C. J. (1964). The effect of growth at elevated temperatures on some heritable properties of Staphylococcus aureus. Journal of General Microbiology 37, I57-I69.

Mitsuhashi, S., Morimura, M., Kono, K. \& Oshima, H. (1963). Elimination of drug resistance of Staphylococcus aureus by treatment with acriflavine. Journal of Bacteriology 86, 162-164.

MOORE, B. (1960). A new screen test and selective medium for the rapid detection of epidemic strains of Staphylococcus aureus. Lancet ii, 453-458.

Novick, R. P. (1963). Analysis by transduction of mutations affecting penicillinase formation in Staphylococcus aureus. Journal of General Microbiology 33, 121-136.

Novick, R. P. (1967). Penicillinase plasmids of Staphylococcus aureus. Federation Proceedings 27, 29-38.

Novick, R. P. (1969). Extrachromosomal inheritance in bacteria. Bacteriological Reviews 33, 210-263.

Richmond, M. H. (1968). The plasmids of Staphylococcus aureus and their relation to other extrachromosomal elements in bacteria. In Advances in Microbial Physiology, vol. 2, pp. 43-38. Edited by A. H. Rose and J. F. Wilkinson. New York and London: Academic Press.

Richmond, M. H., \& JoHN, M. (I964). Co-transduction by a staphylococcal phage of the genes responsible for penicillinase synthesis and resistance to mercury salts. Nature, London 202, I360-1361.

Richmond, M. H., Parker, M. T., Jevons, M. P. \& John, M. (1964). High penicillinase production correlated with multiple antibiotic resistance in Staphylococcus aureus. Lancet i, 293-296.

RountreE, P. M. (1959). Changes in the phage-typing patterns of staphylococci following lysogenization. Journal of General Microbiology 20, 620-633.

Serwin-MASSIEU, M. (I96I). Spontaneous appearance of sectored colonies in Staphylococcus aureus cultures. Journal of Bacteriology 82, 316-317.

Swanstrom, M. \& Adams, M. H. (195I). Method for production of high titer phage stocks. Proceedings of the Society for Experimental Biology and Medicine 78, 372-375.

Weaver, J. R. \& Pattee, P. A. (1964). Inducible resistance to erythromycin in Staphylococcus aureus. Journal of Bacteriology 88, 574-580.

Wood, W. B. \& Henninger, Melva (1969). Attachment of tail fibers in bacteriophage T4 assembly: Some properties of the reaction in vitro and its genetic control. Journal of Molecular Biology 39, 603-6I 8 . 